\title{
Intravitreal Ranibizumab Alone or Ranibizumab Combined with Thermal Laser Therapy for Diffuse Diabetic Macular Edema
}

\author{
Ashraf Mohammed Gad Elkareem \\ Ophthalmology Department, Faculty of Medicine, Al-AzharUniversity, Assiut Branch, Egypt \\ E-mail: silicon2030@gmail.com, Tel: +201060293796
}

\begin{abstract}
Background: Diffuse diabetic macular edema (dDME) is one of the most frequent squeal of diabetes mellitus and deteriorates visual acuity in the working group of population.

Purpose: to compare the effectiveness of intravitreal ranibizumab alone or ranibizumab combined with thermal laser therapy for treatment of diffuse diabetic macular edema.

Patients and methods:forty five eyes of 45 patients suffering from diffuse diabetic macular edema were requriuted and classified into two groups; intravitreal ranibizumab alone group (IR group) included 24eyes of 24 diabetic persons, injected with $0.5 \mathrm{mg}$ ranibizumab $(0.1 \mathrm{ml})$ at baseline, $1 \mathrm{st}$ month, and 3rd month. A twenty-one eye of 21 diabetic patients was injected with $0.5 \mathrm{mg}$ ranibizumab at baseline, $1 \mathrm{st}$ month, and $3 \mathrm{rd}$ month followed with macular grid argon laser photocoagulation three weeks after the 1st injection (combined group).

Visual acuity as log MAR value, central macular thickness (CMT) measured with optical coherence tomography (OCT), and intraocular pressure (IOP) were assessed at baseline, 3 and 6 months post-injection.

Results: the baseline log MAR visual acuity and macular thickness significantly improved in both groups at three, and six months post-injection. However, the combined group showed more improvement with stable results at the end of follow up period of six months. The mean IOP was $14.1 \pm 1.3 \mathrm{mmHg}$ and $13.9 \pm 1.4 \mathrm{mmHg}$ at the end of follow up in IR and combined groups respectively.
\end{abstract}

Conclusion: both groups achieved improvement of visual acuity and reduction of the macular thickness but the effect was more pronounced and long-lasting in the combined therapy group.

Keywords: Ranibizumab, diabetic macular edema, argon laser, diabetic retinopathy, diabetes mellitus.

\section{INTRODUCTION}

Visual deterioration in diabetic retinopathy (DR) patients is related to the development of macular edema ${ }^{(1)}$. Prolonged duration of diabetes and poor control of blood sugar are the main risk factors associated with progression of DR and the occurrence of diabetic macular edema $(\mathrm{DME})^{(2)}$. The main pathology involved in the development of DME is microvascular leakage secondary to breakdown of the inner blood retinal barrier with increased vascular permeability, these will lead to accumulation of fluid in the retinal layers ${ }^{(3)}$.

Although its specific mechanism of action is still unclear, macular laser photocoagulation remains the gold standard treatment of $\mathrm{DME}^{(4)}$. The Early Treatment Diabetic Retinopathy Study (ETDRS) demonstrated that focal/grid macular laser treatment reduced the risk of visual loss in 50\% of the studied patients, but fails to improve visual acuity especially in patients with diffuse $\mathrm{DME}^{(4)}$. However, other recent studies demonstrated good visual restoration in about $31 \%$, and visual deterioration in about $19 \%$ of laser treated patients ${ }^{(5)}$.

Vascular endothelial growth factor (VEGF) is the main mediator involved in the pathogenesis of DME leading to increased retinal vascular permeability ${ }^{(6)}$. Hence the use of anti-VEGF agents as a first-line therapy for the treatment of DME was suggested ${ }^{(7)}$. Although the effectiveness of anti-VEGF as a monotherapy for DME, some studies have shown that a Significant number of patients still have persistent macular edema after multiple monthly injections ${ }^{(7,8)}$.

\section{AIM OF THE STUDY}

It is to evaluate the effectiveness of intravitreal injection of ranibizumab alone or combined with macular laser therapy for treatment of diffuse diabetic macular edema.

\section{PATIENTS AND METHODS}

This is a randomized prospective comparative study carried out between November 2017 and October 2018 and recruited forty-five eyes of 45 patients having diffuse DME according to the ETDRS criteria. The study was carried out in the Ophthalmology Department, Al-Azhar University Hospital, Assiut.The study was done after approval of the Research and Ethical Committee, School of Medical Sciences, AlAzhar University, Egypt. Informed consent was taken from each patient.

These patients were divided randomly into two groups; intravitreal ranibizumab group (IR group) included 24eyes of 24 persons with type 2 diabetes mellitus (DM), 15 males and 9 females, injected with $0.5 \mathrm{mg}$ ranibizumab $(0.1 \mathrm{ml})$ at baseline, $1^{\text {st }}$ month, and $3^{\text {rd }}$ month. A twenty-one eye of 21 patients with type 2 DM, 13 males and 8 females, was injected with $0.5 \mathrm{mg}$ ranibizumab at baseline, $1^{\text {st }}$ month, and $3^{\text {rd }}$ month and grid argon laser photocoagulation was done three weeks after the baseline injection (combined group). 
All included patients had diffuse macular edema with central macular thickness (CMT) $\geq 290$ microns by the optical coherence tomography (OCT).

Excluded from this study, patients with macular edema due to other causes than diabetes, previous vitrectomy, laser treatment of the macula, intravitreal injection of anti-VEGF within the last 6 months. Patients with chronic renal disease, hypertension, or hyperlipidemia are excluded from our study. Patients with cataract as well as known glaucoma patients are also excluded from the study.

All patients had a complete ophthalmic examination, including, BCVA measured on decimal chart and converted into log MAR values at baseline, one, three, and six months of follow up. Slit lamp examination of the anterior segment, fundus examination with the indirect ophthalmoscope and +90D lens, and intraocular pressure (IOP) measurement by the applanation tonometry was done for all patients at each visit. Optical coherence tomography (Time Domain OCT) was done at baseline, 3, and 6 months post-injection.

\section{Procedure:}

Intravitreal ranibizumab (Lucentis; Genentech, South San Francisco, CA) injections were done in the operating room under complete aseptic condition. Disinfection of the ocular surface and eyelids and draping was done for every patient then $0.5 \mathrm{mg}(0.1 \mathrm{ml})$ of ranibizumab was injected slowly with a 27-gauge needle $4.0 \mathrm{~mm}$ inferotemporal to the limbus in phakic eyes into the mid-vitreous cavity.

Visualization of the fundus by the use of indirect ophthalmoscopy was done to ensure proper intravitreal drug delivery and to visualize the optic nerve head perfusion. Paracentesis was done in selected cases in order to minimize the increase of IOP.

Macular grid photocoagulation was done three weeks after the $1^{\text {st }}$ injection in the combined group patients. By using green laser we delivered two rows inside the temporal vascular arcades of 100 micron spot size with one spot size apart with a sufficient power to just bleach the retinal surface leaving 900 microns around the center of the foveal avascular zone without treatment. Two-three rows of laser was applied outside the temporal vascular arcade of 200 micron spot size with one spot size apart. A topical gatifloxacin eye drops(Zymar; Allergan, Irvine, California, USA) was given to all patients 4 times/day for 5 days after the injection with IOP lowering topical drops in cases with an increase of IOP.

Patients were instructed to come to the outpatient clinic at $2^{\text {nd }}$ day post-injection to evaluate serious adverse effect like endophthalmitis and IOP elevation. B-blocker eye drops were given for each patient in the first week after injection and post-laser as a prophylaxis against spikes of IOP elevation
Follow up then scheduled at $1^{\text {st }}$ week, 1 month postoperatively then monthly till the $6^{\text {th }}$ month after treatment.

\section{Statistical analysis}

Continuous data were analyzed by mean and standard deviation (Mean $\pm \mathrm{SD}$ ) while categorical variables were described by number and percent $(\mathrm{N}$, $\%)$.The Chi-square test used to compare between categorical variables and Wilcoxon-Mann- Whitney test used to compare between continuous variables. A $p$ $<0.05$

was considered statistically significant. Analyses were done with the SPSS 20.0 software package for windows (SPSS Inc., Chicago, Illinois, USA).

\section{RESULTS}

The demographic data of the patients included in the study groups are shown in table 1 .

Forty-five patients with type $2 \mathrm{DM}$ had ME were enrolled in this study. There were $62.5 \%$ male and $37.5 \%$ female patients in the IR group while in the combined group there were $61.9 \%$ male and $38.1 \%$ female patients.

Table 1: showing the Demographic date of patients in the two studied groups.

\begin{tabular}{|l|c|c|}
\hline \multicolumn{1}{|c|}{ Variable } & IR group & $\begin{array}{c}\text { Combined } \\
\text { group }\end{array}$ \\
\hline $\begin{array}{l}\text { No of } \\
\text { patients }\end{array}$ & 24 & 21 \\
\hline No of eyes & 24 & 21 \\
\hline $\begin{array}{l}\text { Age } \\
\text { (mean+SD) }\end{array}$ & $\begin{array}{c}58.12 \pm 7.24 \\
\text { years }\end{array}$ & $\begin{array}{c}60.04 \pm 8.22 \\
\text { years }\end{array}$ \\
\hline Male/Female & $15 / 9$ & $13 / 8$ \\
\hline Baseline IOP & $\begin{array}{c}14.65 \pm 2.1 \\
\mathrm{mmHg}\end{array}$ & $\begin{array}{c}13.95 \pm 1.92 \\
\mathrm{mmHg}\end{array}$ \\
\hline $\begin{array}{l}\text { Baseline Log } \\
\text { MAR }\end{array}$ & $0.8 \pm 0.45$ & $0.8 \pm 0.29$ \\
\hline $\begin{array}{l}\text { Baseline } \\
\text { CMT }\end{array}$ & $\begin{array}{c}405.1 \\
\pm 90.2 \mathrm{um}\end{array}$ & $\begin{array}{c}420.8 \pm 100.12 \\
\text { um }\end{array}$ \\
\hline
\end{tabular}

\section{A- Changes in visual acuity over the follow up period:}

Visual acuity measured as log MAR values in the IR group, when comparing the baseline visual acuity with that at the end of follow-up period, there was a significant improvement in vision and some patients achieved improvement of two lines at the end of six months. In the combined group, there was a significant improvement in vision when comparing the baseline reading with the six months reading; with an average gain in visual acuity of two or more lines. Vision gain was achieved in both groups throughout the follow-up period with no significant difference between them but the effect was more pronounced and long lasting in the combined group than the IR group(Table 2). 
ejhm.journals.ekb.eg

Table 2: changes of Log MAR visual acuity in both groups over the follow up period

\begin{tabular}{|c|c|c|c|c|c|}
\hline & \multicolumn{2}{|c|}{ IR group } & \multicolumn{2}{|c|}{ Combined group } & \\
\hline & log MAR value & P-value & log MAR value & P-value & P-value both groups \\
\hline Baseline & $0.8 \pm 0.47$ & & $0.8 \pm 0.29$ & & \\
\hline 1 month & $0.6 \pm 0.24$ & 0.007 & $0.5 \pm 0.32$ & 0.0021 & 0.343 \\
\hline 3 months & $0.5 \pm 0.65$ & 0.055 & $0.4 \pm 0.63$ & 0.0019 & 0.381 \\
\hline 6 months & $0.5 \pm 0.39$ & 0.036 & $0.4 \pm 0.24$ & 0.0018 & 0.442 \\
\hline
\end{tabular}

\section{B- Central macular thickness (CMT)changes:}

The central macular thickness improved in both groups without statistically significant difference between them in the first three months post-injection, however the combined group achieved the highest reduction in the macular thickness at the end of follow-up period. This difference was not statistically significant (Table 3).

Table 3: changes in the central macular thickness (CMT) during the follow-up time.

\begin{tabular}{|l|c|c|l|l|l|l|}
\hline & \multicolumn{3}{c}{ IR group } & \multicolumn{3}{c|}{ Combined group } \\
\hline & baseline & \multicolumn{1}{|c|}{ 3 months } & \multicolumn{1}{c|}{ 6 months } & baseline & 3 months & 6 months \\
\hline CMT & $405.1 \pm 90.2$ & $320.3 \pm 76$ & $245.1 \pm 102.2$ & $430.8 \pm 100.12$ & $285.6 \quad \pm 59.6$ & $223.3 \pm 48.4$ \\
\hline P-value & & 0.0047 & 0.0023 & & 0.0031 & 0.0011 \\
\hline
\end{tabular}

\section{C- Intraocular pressure (IOP):}

The IOP did not increase to a higher levels requiring treatment in both groups.

\section{Adverse effects:}

Persistence of macular edema was responsible for the deterioration of the visual acuity in four patients one in the combined group and three in the IR group.

Cataract formation was observed in one patient in the combined group at the end of follow-up period and scheduled for cataract surgery. One case of endophthalmitis occurred in the IR group.

\section{DISCUSSION}

Diabetic macular edema (DME) has an estimated prevalence ranging from $0-3 \%$ in persons diagnosed as diabetics for the first time, this incidence increases to $30 \%$ after 10 years of onset of diabetes ${ }^{(3)}$.

In the previous decades macular laser photocoagulation was the standard therapy of DME, nevertheless, it has a suboptimal effect in some patients, especially those with diffuse DME and fails to regain useful vision ${ }^{(9)}$.

The vitreous and retinal tissue of diabetic persons has elevated levels of vascular endothelial growth factor (VEGF), an angiogentic factor, which play a crucial role in the pathogenesis and persistence of DME. Consequently, pharmacological down-regulation of the VEGF through intravitreal injection of anti-VEGF drugs becomes one important option for the treatment of $\mathrm{DME}^{(10)}$.

Ranibizumab, one of the anti-VEGF agents, is the first antigen-binding humanized monoclonal antibody segment that has the FDA approval for treatment of neovascular age-related macular degeneration and DME and it binds and blocks all isoforms of VEGF-A (11).

The present study showed that the mean visual acuity significantly improved in the combination therapy group as well as in the ranibizumab alone group in the first three months post-injection and the improvement continued over the follow-up period but it was more pronounced and long lasting in the combination group.

Our study also demonstrated that the CMT was decreased throughout the time of the study both in the combination therapy and the ranibizumab only groups, but the combination therapy group achieved a greater reduction of the CMT that persist until the end of the follow-up time.

As an explanation for greater improvement of the visual acuity and CMT in the combination therapy group than the monotherapy group in this study is that diffuse DME is caused by a widespread microvascular leakage and considered an advanced and chronic stage of DR, so adding supplemental treatment to the antiVEGF therapy would potentiate its therapeutic effect.

Macular laser photocoagulation seems to be responsible for the improved functional and anatomical results in the combination therapy group. Laser demolition of some photoreceptors, which deplete a high amount of oxygen, will preserve and increase the oxygen supply to the inner retinal layers. Consequently, this would decrease the retinal anoxia and reduce further releases of VEGF, subsequently improving the results and reducing the recurrence rate of DME.

Hence, the use of macular laser photocoagulation with intravitreal ranibizumab injection is practically more favorable in retrieving good visual and anatomical results than ranibizumab or laser alone.

Wang etal., in a meta-analysis study was trying to demonstrate the efficacy of intravitreal ranibizumab injection for treatment of DME, they concluded that ranibizumab alone or combined with laser were more advantageous than laser monotherapy ${ }^{(12)}$.

Some previous reports showed that macular laser photocoagulation monotherapy decreased visual loss in 
patients with diffuse DME ${ }^{(4)}$. Other studies, however, showed that visual acuity deteriorated by about three lines or more in about quarter of eyes with diffuse DME after macular laser photocoagulation ${ }^{(13)}$.

READ-2 is a multicenter clinical study established to compare ranibizumab with macular laser, alone or in combination, for the treatment of DME. The study found that the ranibizumab group achieved a significant gain in visual acuity compared with patients who had only laser treatment after six months of the study. It was also found that the combination therapy group didn't have statistically significant different results than the monotherapy groups (laser alone or ranibizumab alone) as regard the visual acuity changes. As regard the anatomical results, the study revealed that ranibizumab alone or combined with laser resulted in greater reduction of the CMT than laser monotherapy ${ }^{(14)}$.

Results from the RESTORE study demonstrated that ranibizumab alone or combined with laser were superior to laser monotherapy in improving visual acuity and reducing the CMT throughout the 12 months and revealed that at one year, no differences were found between the ranibizumab alone or combined with laser regarding the anatomical and functional results ${ }^{(15)}$.

The results of RESTORE study are in line and consistent with the Diabetic Retinopathy Clinical Research Network (DRCR.net) and RESOLVE trials.

The DRCR.net trial revealed that intravitreal ranibizumab injection adjunctive with macular laser treatment either prompt or deferred was significantly more efficient than laser monotherapy in restoring good visual and anatomical results in DME patients after 12 months of therapy. This trial suggested that combined treatment could provide a more potent regimen for treatment of DME, taking into consideration the multifactorial etiology of the disease ${ }^{(16)}$.

The RESOLVE trial also showedthat ranibizumab yielded a fast and long-lasting improvement in visual acuity results when compared with sham in a time of one year follow-up ${ }^{(17)}$.

Some previous trials ${ }^{(18,19)}$ used laser therapy within one week after the first intravitreal ranibizumab injection.

The accumulation of much fluid in the retinal tissues in patients suffering from diffuse macular edema may make thermal therapy more difficult, less efficient, and requiring the delivery of more laser energy than usual that could result in more visual deterioration. That is why in our study, we applied laser treatment three weeks after the first ranibizumab injection allowing the retina to get rid of some retinal fluid facilitating and making the laser application more easy and efficient.

Our results are in agreement and in line with the previously mentioned studies concerning the anatomical and functional results.

Whereas laser therapy still the standard treatment of DME, the appearance of anti-VEGF agents have opened up a new epoch in the treatment of DME that could enhance, limit, or even replace thermal therapy ${ }^{(9)}$.

In conclusion the use of more than one line of treatment in combination for patients with diffuse DME could provide more sustained results with the need for less frequent injections and decreasing the recurrence or persistence rate of DME. Further studies with large number of patients and longer follow-up periods are needed to evaluate the safety and efficacy profile of combination therapy for DME over a longer time span.

\section{REFERENCES}

1.Klein R, Klein BE, Moss SE, Davis MD, DeMets DL (1984): The Wisconsin epidemiologic study of diabetic retinopathy, IV: diabetic macular edema.Ophthalmology,91:1464-1474.

2.Moss SE, Klein R, Klein BE (1998): The 14-year incidence of visual loss in adiabetic population. Ophthalmology, 105:998-1003.

3.Klein R, Klein BE, Moss SE, Cruickshanks KJ (1995): The Wisconsinepidemiologic study of diabetic retinopathy. XV. The long-term incidenceof macular edema. Ophthalmology, 102:7-16.

4.Early Treatment Diabetic Retinopathy Study Research Group (1985): Photocoagulation for diabetic macular edema: Early Treatment Diabetic Retinopathy Study report number 1. Arch Ophthalmol.,103:1796-806.

5.Diabetic Retinopathy Clinical Research Network (2009): Three-year follow-up of a randomized trial comparing focal/grid photocoagulation and intravitreal triamcinolone for diabetic macular edema. Arch Ophthalmol.,127: 24551.

6.Grant MB, Afzal A, Spoerri P, Pan H, Shaw LC, Mames RNet al. (2004). The role of growth factors in the pathogenesis of diabetic retinopathy. Expert,13:1275-93.

7.Nguyen QD, Brown DM, Marcus DM, Boyer DS, Patel S, Feiner Let al.(2012): Ranibizumab for diabetic macular edema: Results from 2 phase III randomized trials: RISE and RIDE. Ophthalmology ,119:789-801.

8.Bressler SB, Ayala AR, Bressler NM, Melia M, Qin H, Ferris FL et al. (2016):Persistent macular thickening after ranibizumab treatment for diabetic macular edema with vision impairment. JAMA Ophthalmol.,134:278-85.

9. Ford J A, Lois N, Royle P, Clar C, Shyangdan D, Waugh N (2013): Currenttreatments in diabetic macular oedema: systematic review and metaanalysis.BMJ Open, 3(3): 2269.

10.Lally DR, Shah CP, Heier JS (2016): Vascular endothelial growth factor anddiabetic macular edema. SurvOphthalmol.,61(6:)759-68.

11.Chun DW, Heier JS, Topping TM, Duker JS, Bankert JM (2006): A pilot study of multiple intravitreal injections of ranibizumab in patients with center-involving clinically significant diabetic macular edema. Ophthalmology, 113:1706-1712.

12.Wang H, Sun X, Liu K, Xu X (2012): Intravitreal ranibizumab (Lucentis) for the treatment of diabetic macular edema: a systematic review and meta-analysis of randomized clinical control trials. Cur Eye Res., 37: 66170.

13.Lee CM, Olk RJ(1991): Modified grid laser photocoagulation for diffuse diabetic macular edema: long term visual results. Ophthalmology, 98:1594-602. 
14.Nguyen QD, Shah SM, Khwaja AAet al. (2010):READ2 Study Group. Two-year outcomes of the ranibizumab for edema of the mAcula in diabetes (READ-2) study. Ophthalmology, 117:2146-51

15. Mitchell P, Bandello F, Schmidt-Erfurth U, Lang GE, Massin P etal. (2011): The RESTORE study: Ranibizumab monotherapy or combined with laser versus laser monotherapy for diabetic macular edema. Ophthalmology, 118: 615-25.

16. Diabetic Retinopathy Clinical Research Network, Elman MJ, Aiello LP et al. (2010): Randomized trial evaluating ranibizumab plus prompt or deferred laser or triamcinolone plus prompt laser for diabetic macular edema. Ophthalmology, 117:1064-77.

17.Massin P, Bandello F, Garweg Jet al. (2010): Safety and efficacy of ranibizumab in diabetic macular edema (RESOLVE study): a 12-month, randomized, controlled, double masked, multicenter phase II study. Diabetes Care, 33:2399 - 405 .

18.Berger A, Sheidow T, Li R, Rehel B, Takacsy FDet al. (2013): A canadian 12-month, PhIIIb study of ranibizumab combination or monotherapy in visual impairment due to diabetic macular edema:preliminary analysis ("RESPOND'), Can J Diabetes, 37: S48.

19.Comyn O, Sivaprasad S, Peto T, Neveu MM, Holder GEet al. (2014): A randomized trial to assess functional and structural effects of ranibizumab versus laser in diabetic macular edema (the LUCIDATEstudy). Am J Ophthalmol., 157: 960-970. 